\title{
THE HISTORICALLY REALISED EQUITY RISK PREMIUM AS A GUIDE TO FUTURE EXPECTATIONS IN AN EMERGING MARKET: THE CASE OF SOUTH AFRICA
}

\author{
Jesse de Beer \\ University of the Free State \\ debeerja.blms@mail.uovs.ac.za
}

August 2007

\begin{abstract}
The concept of an equity risk premium (ERP) is fundamental to modern financial theory and central to every decision at the heart of corporate finance. Efforts to quantify ERP are well rewarded by insights into the stability and dynamics of long-term investment performance. Such efforts require the quantification of both historically realised (ex post) and expected future (ex ante) premiums. Finding an appropriate proxy for the expected (ex ante) ERP remains a challenging aspect. One widely used application is the use of long-term averages of observed market premiums as a proxy for expected returns. The aim of this paper is to analyse the appropriateness of the historical methodology of estimating expected ERP in the South African context. The analysis in this paper suggests that analysing past historical figures remains useful in the SA context. This is supported by the results of the statistical analysis, showing stationarity of the ERP time-series, meaning that the true mean does not change over time. This implies that the historical average mean may be used as a proxy for the long-run expected ERP. However, the well-documented problems relating to large standard errors (predictability problem) and relevance due to changing circumstances are also evident in the SA data. Thus, investors would be well advised to analyse the past and apply informed judgments as to future differences, if any, when attempting to arrive at fair forecasts.
\end{abstract}

\section{Keywords:}

Equity risk premium, supply-side models, emerging markets, bond and equity market returns, expected returns 


\section{INTRODUCTION}

The concept of an equity risk premium ( $\varepsilon R P$ ), the incremental return of certain equity market components relative to certain fixed-income components (usually bonds), is fundamental to modern financial theory and central to every decision at the heart of corporate finance. Efforts to quantify ERP are well rewarded by insights into both the stability and the dynamics of longterm investment performance. Such efforts require the quantification of both historically realised (ex post) and expected future (ex ante) premiums. Finding an appropriate proxy for the expected (ex ante) ERP remains a challenging aspect. One possible and widely used application is the use of long-term averages of observed market premiums as a proxy for expected returns. Although this is still widely used and advocated in leading textbooks, alternative approaches have emerged recently. These include the use of so-called supply-side methods, which estimate expected ERP figures that take several 'fundamental' factors into account. These are fast gaining ground.

The ERP literature favours the US experience, resulting in a potential survivorship bias in the data used in empirical studies. Consequently, empirical results from other countries are of particular interest, and this is especially true for emerging markets. However, researchers are faced with unique challenges in this regard, mainly concerning the availability and quality of long-term data on share and bond returns. A related concern is the fact that most emerging markets are in fact re-emerging markets, potentially resulting in an overly optimistic picture of future returns by looking at historically realised returns. Another problem is that the risk premium of an emerging market may change over time, as its degree of integration into world capital markets changes, as is widely recognised in the literature.

The aim of this paper is to complement and extend the existing ERP literature, by analysing the SA experience - specifically, the appropriateness of the historical methodology of estimating future expected $\varepsilon R P$ in the South African context. In this regard, the literature and available empirical evidence is reviewed. Results from existing studies are extended and complemented by extending the sample period and analysis of available data.

This paper is structured as follows:

- The general concept of 'equity risk premium', as well as a description of the methodology of using historical returns to predict future estimates, will be discussed in Section 2.

- The next section briefly reviews the different forward-looking approaches to estimating the ex ante equity risk premium in the US context.

- Section 4 contains an evaluation of the use of the historical approach as a guide to future ERP expectations in the SA context in terms of the issues identified in Section 2.

- It also includes a brief statistical investigation into the time series properties of historical returns on equities and bonds, as well as the resulting ERP figures.

- The last section comprises the conclusion. 


\section{ESTIMATING THE EXPECTED ERP: THE HISTORICAL APPROACH}

\subsection{Definitions and rationale for the historical approach}

As noted in the introduction, the equity risk premium refers to the incremental return of certain equity market components relative to certain fixed-income components. This return may either refer to a historically realised (ex post) ERP or the return that equity holders expect to achieve on average above risk-free assets (ex ante or expected ERP). The latter is a forward-looking measure, arguably residing in the minds of investors and influencing their pricing of assets in the market (Bradfield, Firer \& Abrahams, 2002).

Since expected returns are not directly measurable, long-term averages of observed market premiums are often used as a proxy for expected returns. This is based on an assumption that arbitrage will result in 'surprises' (deviations between expected returns and realised returns) being zero-mean and unpredictable, in which case realised returns would provide an unbiased estimate of what returns had been expected for that period. In support of this approach, it is often argued that, on average, the market is right. Thus, although the equity gain above bonds in a particular year is not considered to be the market risk premium, the incremental return of stocks over bonds over a number of years is considered to be a good estimator of the required equity risk premium.

Roger Ibbotson can arguably be credited with the origin of the historical methodology of estimating the expected ERP. The 1976 study by Ibbotson and Sinquefield was the first to explicitly measure historical risk premiums. Their calculated historical premiums came to be used in practice and theory as the risk premium input into the CAPM models. They later showed how historical data may be used to simulate probability distributions of future returns. In 1976, the historical ERP appeared to most as a wildly optimistic forecast for future returns, given the stock market crash of 1973-74 and that double-digit inflation and erosion of capital were fresh in the public imagination in 1976. In fact it was not: ERP since 1976 has nearly matched the estimate made at the time. These results were probably one of main reasons for the popularity of historical methodology. Today, the Ibbotson Associates Yearbook is often regarded as the definitive study of historical US ERP. Other sources include the DMS global database, which has provided annual returns on stocks, bonds, bills, inflation and currencies for 17 countries since 1900 (Dimson, Marsh \& Staunton, various issues).

The availability of long-run, high quality US capital markets data and the lack of such data for most other countries have caused some authors to use US historical figures to calculate ERP for other countries. For example, Bowman (2001) estimates the market risk premium in Australia by referring to evidence from United States capital markets, with explicit adjustments for taxation, market differences and country risk. Damodaran (2002) advocates the use of such an approach for emerging markets, given the challenges resulting from data availability, data quality and changes in valuation levels due to integration in international capital markets. Some studies do calculate ERP figures directly from emerging market data, most notably Salomons and Grootveld (2003), who use cross-section capital market data. In the South African context, the most recent studies include those by Bradfield, Firer and Abrahams (2002) and Firer and Bradfield (2002). 


\subsection{A theoretical anchor for a justified ERP figure: The ERP puzzle literature}

The so-called "puzzle research" is often suggested as a theoretical justification for the view that historically realised ERP figures are 'too high' to be used as proxy for expected ERP. ERP puzzle research involves the comparison of historically realised $\varepsilon R P$ figures with a normative anchor for the appropriate size of the ERP. As such, Markowitz's portfolio theory and CAPM provide a theoretical foundation for estimating the magnitude of ERP directly from investor preferences. In their classic and widely discussed 1985 article, Mehra and Prescott (1985) compared ERP implied by preferences with empirical measures provided by historical returns and found the results to be a puzzle. The essence of the puzzle is the inconsistency of the ERPs produced by asset pricing models on the one hand and the historical ERPs realised in the US market, on the other. Specifically, the historically realised ERP for the stock market using 18891978 data appeared to be far in excess of asset pricing theory values based on normal parametrisations of risk aversion. Mehra and Prescott argued that economic models predicted that either the rate of return on stocks should be lower, or the rate of return on fixed income assets should be higher, or both. In fact, their studies justified an equity premium as low as $1 \%$ or less.

This result inspired a stream of finance literature that attempts to solve the puzzle (for example, Constantinides (2002), Constantinides, Donaldson and Mehra (2002), Mehra and Prescott (2003) and Dimson, Marsh and Staunton (2006)). It has involved both relaxing the assumptions underlying the standard theoretical models (the puzzle is the result of 'wrong models') and more carefully interpreting the historical data (the puzzle is due to misleading historical figures). The latter refers to various biases in the data that are generally used to estimate historical figures, especially in the US context (see section 3 in this regard).

\subsection{Limitations of the historical approach and some possible solutions}

Despite widespread continued use, the application of historically realised premiums as a guide to future expectations has come under increased attack. Two potential limitations need to be taken into account when interpreting the historical analyses, namely predictability and relevance. In terms of predictability, two issues are at stake, namely, large standard errors and the time series properties (stationarity or not) of the ERP series. Non-stationarity of the ERP time series implies that realised equity premiums cannot be used as a proxy for expected ERP (see section 4.2). The high volatility of stock and bond returns (and consequent large standard errors) means that standard statistical inference requires wide confidence intervals to be placed around the results.

In terms of relevance, the concern is the fact that changes in capital market and macroeconomic-conditions render the validity of the historical record for predicting future expected long-term returns questionable. Historically realised returns only equal the expected if expected returns are constant and if unexpected returns from trend-wise valuation changes do not distort the in-sample results, even over very long time periods. However, trends in capital markets over time (including new institutions, declining transaction costs, and a widening pool of investors) along with macroeconomic developments (including changing inflation, GDP growth expectations and globalisation) provide the possibility that future capital market behaviour may well deviate substantially from past experience. Thus, average returns often conceal significant time variations in market performance. 
Consequently, some researchers have opted for the adjustment of historical figures. Researchers opting for the adjustment of historical figures use two broad approaches, namely, selecting a valuation-neutral sample period and adjusting realised returns for the estimated repricing impact (llamen, 2003:4). The latter involves the selection of any sample period and adjusting the return for unexpected capital gains. Several recent studies take this approach, notably Dimson, Marsh and Staunton (2002), Fama and French (2002) and Ibbotson and Chen (2003). Each study uses a slightly different way to remove the impact of unexpected capital gains to recover the typical expected ERP over the sample period. All three studies find (adjusted) ERP near $4 \%$ in the US, averaged over very long histories.

Another approach involves conditioning future expectations on stock market prices relative to certain fundamentals, most notably EPS and dividends per share. These studies are inherently forward-looking in nature and are usually referred to as 'supply-side models'. The results of most of these studies point to a smaller (sometimes even zero or negative) equity risk premium over the next few decades for the US.

A final conceptual problem with the historical approach in general and, more specifically, relying on US data, is the so-called survivorship bias. This implies that history may simply have turned out better than expected. For example, the US market survived two World Wars, the Cold War, and the Great Depression and did not suffer the hyperinflation, invasion or other calamities that many other countries did (including Japan, Germany and France). Survivorship bias is often mentioned in the literature as a possible explanation for the so-called ERP puzzle. A more subtle problem is that historical records of successful markets tend to be preserved (see for example Fama and French 2002). Easy data bias is a related problem: researchers are likely to start samples after unusual events (war, hyperinflation, market closure), which often means that assets are cheap at the start of the period and that no comparable turmoil occurs again during the period.

In addition to the above-mentioned problems, forward-looking approaches to estimating expected ERP are conceptually preferable to the historical approach. After all, such a measure should reflect the return expected (required) by investors. Forward-looking approaches to the measurement of the expected $\varepsilon R P$ are the topic of the next section.

\section{ALTERNATIVE APPROACHES: FORWARD-LOOKING APPROACHES}

Forward-looking approaches are based either on projections implied by current stock prices relative to earnings and dividends (supply-side models) or, on the other hand, on surveys of the expectations of investors, analysts and financial economists.

The supply-side approach is intertwined with debates about where the stock market is heading and whether it is over- or undervalued. Most of the related studies were published around 2000 and were to a large extent motivated by the US stock market experience at the time: the Dow Jones Industrial Average increased in value by more than 200 percent in a five year period, while corporate profits rose, during the same period, by less than 60 percent. In general, authors using this kind of model, focus on the constant dividend, Gordon Growth Model (1962). In terms of this model, stock prices may be viewed as discounted values of expected future cash flows. Consequently, it is an accounting identity that higher stock prices and realised returns reflect either higher earnings growth expectations (the 'new era' argument) or lower required returns (llamen, 2003:6). Both arguments are reflected in the literature. 
For example, Fama and French (2002) found that stocks produced unexpected capital gains for 1951-2000 and that the average realised stock return exceeded the expected future stock return. The prime source of the unexpected capital gain was believed to be a decline in the required stock returns. Several papers (Diamond, 1999 and Siegel, 1999) suggest that the decline in the expected stock return is in part permanent, due to wider equity market participation by individuals and institutions, plus lower costs of obtaining diversified equity portfolios from mutual funds. Other explanations of the variation in expected returns are said to be the rational variation in response to macroeconomic factors. In this regard, Lettau, Ludvigson and Wachter (2004) proposed the fall in macroeconomic risk or the volatility of the aggregate economy as an alternative justification for the declining risk premium and for persistent high stock market valuations.

On the other hand, several authors postulated investor irrationality and the market being overvalued with either a significant fall being imminent (a 'crash' or 'burst bubble') or a long and depressing slide of negative returns as it corrects over time. These authors, using so-called supply-side models, estimated future ERP values at much lower than the historical average. This includes a number of studies that have examined the predictability of future returns using a variety of valuation ratios (dividend yields, $P / E$ ratios).

For example, Campbell and Shiller $(1998,2001)$ show that extremely low D/P ratios and/or extremely high $P / \varepsilon$ ratios forecast future declines in stock prices, as these valuation ratios are thought to be reliably mean-reverting over long periods of time. Based on the historically high market $P / \varepsilon$ ratios in the late 1990 s, they predict that US equities will lose $40 \%$ of their value over the period 1997-2006.

Several economists have used the Gordon model as the basis for their responses to the Social Security's Administrative Office of the Actuary (OACT). These include Johan Campbell, Peter Diamond and John Shoven. Their estimates differ from the geometric equity premium estimate, around 1.5 to $2.5 \%$ (Campbell), to 3-3.5\% (Shoven). Arnott and Ryan (2001) estimate a negative geometric long-horizon conditional equity risk premium. For Arnott and Bernstein, the current $\varepsilon R P$ is zero, i.e. they expect stocks and (risk-free) bonds to return the same amounts.

Other supply-side studies include that of Siegel (1999), which predicted that the risk premium would decline in future because of low current dividend yields and high equity valuations. Roughly similar approaches and conclusions may be found in Siegel (1999, 2002), Glassman and Hassett (1999), Asness (2000), Shiller (2000), Arnott and Ryan (2001), Campbell and Shiller (2001), Claus and Thomas (2001), Arnott and Bernstein (2002), Fama and French (2002), Ritter and Warr (2002), Ibbotson and Chen (2003), Ilamen (2003) and Polk, Thompson and Vuolteenaho (2003).

On the other hand, Ibbotson and Chen (2001 and 2002) found ERP estimates roughly similar to the historically realised average using supply-side (Gordon-based) models. In their (2001) study they use two models, with the historical growth in earnings and growth in GDP per capita as proxies for dividend growth. They obtained estimates of the expected equity risk premium of $5.9 \%$ and $6.2 \%$, respectively. In their 2002 study, they segmentised the historical equity returns into different components based on six different models, applying historical equity returns and earnings data, ranging from 1926 to 2000 . They found that the long-term supply of equity risk premium is only slightly lower than the straight historical estimate.

The wide discrepancies in results partly reflect the fact that, while the Gordon dividend discount model formula is simple, applying it sensibly is tricky. Essentially, the researcher has to decide 
on the appropriate dividend payout ratio, as well as a sensible proxy for the expected growth rate $(\mathrm{g})$. The simplest application is the assumption of a constant growth rate of dividends postulating that the expected return equals the current dividend yield plus the dividend growth rate. The main debate is on estimations of $\mathrm{g}$, since this is the least-anchored input. Even with providing proxies for the observable input, DY is ambiguous (for example, how to treat share repurchases).

Several applications are found in the literature, including simply using the historical growth rate for real earnings or dividends as a proxy for the future growth rate of real dividends. Other applications include adjusting the growth rate (e.g. if current dividends are low relative to earnings, then we would expect the future rate of growth for earnings to be higher than it has been historically) and using proxies such as the historical (with various adjustments possible) GDP growth per capita as proxy for $g$.

As is evident from the above discussion, forward-looking (based on supply-side models), ERP estimates are also fraught with problems. These include the large standard error problem found when historically realised premiums are used. In the South African context, Digby, Firer and Gilbert (2006) estimate a forward-looking ERP measure, using two fundamental models that utilise dividend and earnings growth as unbiased estimators of long-term equity price growth. They found the standard deviation and standard error of the dividend model to be considerably higher than those of realised premiums for the same period. This suggests that the ERP estimate, using historically realised premiums, is more reliable in the South African context.

The most intractable problem in using supply-side models remains the difficulty of estimating future dividends or earnings growth. Some economists have attempted to meet the challenge by eliciting future-oriented information from analysts and other market participants. These include direct survey approaches, in which individuals are asked to provide forecasts of either the equity risk premium or of returns to the various asset classes from which an equity premium forecast may be calculated directly. These initially have given an expected equity risk premium similar to the $7 \%$ historical result. However, the assumed long-term earnings growth rate has a crucial impact on the result in this model and there has been some doubt about the realism of analysts' growth forecasts when seen in the context of expected overall economic growth. Later applications using analysts' near-term forecasts but lining long-term growth up with expected growth in the economy obtained estimates that were more in the $4 \%$ to $5 \%$ range.

In addition to the use of survey data as an input in the Gordon model, surveys were also used to obtain direct estimates of ERP figures. For example, Welch (2000) conducted a survey on the ERP estimations of 226 academic financial economists. Graham and Campbell (2001) conducted a multi-year survey of US corporations' chief financial officers (CFOs).

However, the interpretation of the results of surveys is not straightforward. First, there is a range of definitions and measures of returns and the risk premium. Even with a carefully specified question it is impossible to know whether the question is being interpreted as intended. Second, survey results also seemed to be strongly influenced by historical records and short-run fluctuations. For example, private US investors' subjective returns expectations were especially high in the late 1990s, with the consensus expectation of $19 \%$ on annual returns over the long run (following 5 years of $20 \%-40 \%$ annual returns). Survey results might very well reflect what llamen (2003) calls "hoped-for" returns, as much as required returns.

Third, by their nature, survey results are not necessarily very diagnostic and should be treated with caution. Survey responses can be biased, such as the documented bias in analysts' 
forecasts (Chan, Karceski \& Lakonishok, 2001). Finally, the cross-sectional dispersion of forecasts tends to be as large as the standard error of the mean historical equity premium. For example, no clear consensus emerged from the Welch (2000) financial economists' survey.

\section{USING THE HISTORICAL APPROACH TO GUIDE FUTURE EXPECTATIONS IN THE SA CONTEXT: A CRITICAL ANALYSIS}

As noted in section 2, researchers and investors who want to use historically realised ERP figures as a guide to future expectations are faced with two main challenges, namely the relevance of historical figures (due to changing circumstances) and predictability (complicated by large standard errors and questions about the time series properties of the ERP). As previously noted, in an emerging market context there is the added complexity of structural breaks due to integration into the world economy and the challenges posed by the so-called "re-emerging" status of many markets and the related lack of quality long-term data. The aim of this section is to evaluate critically the extent to which these concerns apply in the SA context. In this regard, the section starts with a brief review of existing ERP studies, using SA data. It also includes a brief review of recent changes in the $S A$ investment environments, possible future changes and the potential impact on future $\varepsilon R P$ that may necessitate adjustments in historical figures. The section concludes with a statistical analysis that examines the time series properties and stationarity of the equity returns, bond returns and resulting ERP series.

\subsection{What we can learn from previous empirical studies}

The most extensive and recent studies in the South African context are those by Bradfield, Firer and Abrahams (2002) and Firer and Bradfield (2002). The analysis in both these studies is based on a data set that covers the period 1925-2000. These studies provide an indication of the magnitude of historically realised SA ERP figures and show the time-varying nature of ERP.

The analysis that follows draws both from comments made in these papers and the author's own analysis of the (extended DMS) data set. This analysis points to several potential problems in using historically realised ERP figures as a guide to expected future returns:

- The magnitude of realised ERP in 'puzzle territory'. The South African risk premium is in line with the risk premiums of the US, at the upper bound of international experience. The longterm average risk premium in South Africa, based on a 76 -year history, is $9.5 \%$ with a standard deviation of $23.5 \%$ (as calculated by Firer \& Bradfield 2002). The equivalent figures for the USA, for the period 1926 to 1999, as calculated by Ibbotson Associates, are a risk-premium of $9.5 \%$ with a standard deviation of $19.9 \%$.

- The time varying nature of the ERP series poses serious challenges for extrapolating historically realised returns into the future. Bradfield, Firer and Abrahams (2002) highlight the slow decline in the estimated market risk premium over the period 1981 to 2000 (3.8\% compared to $9.5 \%$ for the entire period). They ascribe this either to a downscaling of the premium demanded by investors for taking on market risk or to the fact that the particular time period chosen is too short to be able to draw any meaningful conclusions. They also highlight the negative ERP in 1998 (the lowest ever). Again, they attribute it to possible changes in risk perceptions.

- The historical equity risk premium has proved to be an extremely volatile series, as evident 
from the large standard errors of both equity and bond returns and the extreme volatility in equity returns during the 1970 s, as a result of the influence of the volatile gold price. Bond returns range from negative real returns to large positive real returns. This may be ascribed to, among other things, substantial changes in monetary policy during the sample period.

- The above-mentioned results point to the great uncertainty that surrounds the relevance of returns in any short period of time for projecting returns over the long run (the predictability problem discussed in Section 2). This is further illustrated by looking at the returns during the sub-periods 1960-1979, 1981-2000 and 1993-2003. These sub-periods represent extraordinary and often turbulent macro-economic, capital market and political conditions (for example, the introduction of a dual exchange rate system, major political changes and financial liberalisation during the 1990s).

In order to further highlight the danger of relying on historical figures from a relatively short historical period, the following analysis of returns during several sub-periods is provided.

TABLE 1: Real returns, selected sub-periods

\begin{tabular}{lccl}
\hline \multicolumn{1}{c}{ Sample period } & Equity & Bonds & ERP \\
\hline $1960-2002$ & 9.5 & 1.7 & 7.8 \\
$1980-2002$ & 7.4 & 3.7 & 3.7 \\
$1960-1979$ & 12 & -6 & 18 \\
\hline
\end{tabular}

Source: Author's own calculations, using the DMS database

In all cases, the comparisons are directly adapted from DMS (2006) or based on the author's own calculations, using the DMS database.

TABLE 2: Nominal returns, equity and bonds, 1995-2003

\begin{tabular}{ccc}
\hline Year & Equity & Bonds \\
\hline 1995 & 8.6 & 34.6 \\
1996 & 9.2 & 3.1 \\
1997 & -4.3 & 32.3 \\
1998 & -10.7 & 2.6 \\
1999 & 60.6 & 28.9 \\
2000 & -0.5 & 18.9 \\
2001 & 27.0 & 18.4 \\
2002 & -7.7 & 16.3 \\
2003 & 16.6 & 19.0
\end{tabular}

\section{Source: Data provided by Sasfin}

The unusually high ERP for the period 1960-1979 may be attributed to both high equity returns and low and often even negative real bond returns. During this period, negative real bond returns 
were experienced for 11 out of the 20 years.

Before 1986, relatively long periods of consecutive negative bond returns were the order of the day. For example, 1947-1952 (6-year run of negative real returns), 1973-1976 (4 years) and five periods of 3 years of negative consecutive bond returns (1915-1917, 1942-1944, 1964-1966, 1979-1981 and 1983-1985). The longest run of negative real equity returns was three years (1929-1931, 1946-1948, 1950-1952, 1955-1957 and 1996-1998).

In contrast, bonds often outperformed equities during the period 1995-2003. This motivated speculation about a relatively low (in a historical context) or even negative future ERP (see for example, Bradfield, Firer and Abrahams 2002). However, this expectation was not realised. In fact, SA equities outperformed all other world markets for the period 2000-2007 and also comfortably outperformed SA bonds.

However, this result does not mean that the historical evidence should be disregarded. Instead, it emphasises the importance of looking at the long-term history, including the periods presenting different macro-economic and capital market conditions. Due to the availability of a high quality data set covering returns from 1900, valuable insights regarding the future ERP may be gained from analysing historically realised returns. This also implies that the re-emerging market concern (see Jorion and Goetzmann) that observed return distributions are conditioned upon recent re-emergence and, consequently, that a historical analysis will paint an overly optimistic picture of the future, is not valid for the JSE.

Moreover, it also shows an important lesson in the appropriate use of the historical methodology.

The return figures for bonds and equities during the period 1995-2003 (see TABLE 2) provide a case in point. These figures must be seen in the light of the exceptional recent bond returns in SA. For example, the South African bond market outperformed all other asset classes in US dollar terms over the period between 2001 and 2003. This performance may largely be attributed to the interest rate environment and the exchange rate of the Rand. The impact of the 1997/98 emerging crises on SA equity returns during this period should also be taken into account when extrapolating these returns into the future. At present, the macro-economic outlook for SA is considerably more favourable than, for instance, during the 1997/98 period.

The implications are that the time periods shown in TABLE $\mathbf{1}$ and TABL $\mathbf{2}$ are too short to reliably extrapolate realised returns into the future, and this points to the danger of using historical figures from short periods, especially without any adjustments to reflect changing circumstances. Globalisation is of special importance in this regard. The conventional wisdom is that, as globalisation gathers pace and emerging markets are integrated into the global economy, country-specific effects will be increasingly dominated by worldwide trends. This is arguably a basis for challenging the relevance of the historical evidence of the SA context. It definitely means that special care should be taken when extrapolating/comparing historical returns from sub-periods, such as the isolation years, especially 1980-1994, with the experience of 1994 onwards.

However, the structural change that occurred with the re-integration of SA into the world around 1994 is not a valid argument for disregarding historically realised returns. For example, the gold price (an 'international factor') dominated stock returns during the 1970s, part of the isolation years. Furthermore, foreign investors actively traded on the JSE long before 1994 and even during the isolation years of the 1970s to early 1990s. The findings of Salomons and Grootveld (2003) provide supportive evidence in this regard. (Salomons \& Grootveld (2003) explicitly compare the 
magnitude of the historically realised ERP for emerging and developed markets. They use a relatively short time period (1976-2006) and their sample of emerging markets includes SA (data only from 1994).)

They found no difference in the magnitude of ERP before and after market liberalisations. Instead, their results indicate that, on aggregate, the time variation in ERP is largely determined by changes in the global economic business cycle. Although they observed time-varying behaviour in the emerging market ERP data, they "cannot claim the presence of a structural break in the data". Makina and Negash (2005), dating stock market liberalisation and structural change in the JSE context, also confirm that dating is not a clear-cut empirical issue. For instance, they found a structural break in volume traded in 1990, but not in stock market prices.

Changing sentiment (and the resulting change in equity returns) towards emerging markets in the period 1997-1998 versus 2003-2006 provide anecdotal evidence in this regard. At the very least, it points to the fact that increased financial globalisation does not necessarily mean a structural break in ERP figures. As noted by Harvey (2002) and Salomons and Grootveld (2003), the true underlying process between capital market development and the equity risk premium may be more dynamic and complicated.

The possible impact of domestic macro-economic changes, such as changes in inflation and interest rates and the magnitude and stability of economic growth, should also be considered. The US literature points to the increase in overall economic stability as an important explanatory factor in boosting stock prices. The expectation of higher and more stable economic growth (at least in comparison to the 1980-1995 period) is one possible reason for expecting higher future equity prices in SA. It may also be argued that the expected future growth rate of SA's GDP is probably higher than the realised mean (especially for the period 1981-2000).

Currently, SA inflation rates and interest rates are relatively low in a (near-term post-1973) historical context. These changes may potentially have an important impact on the relative riskiness of stocks and bonds and, consequently, asset prices and the ERP. This is especially true if they signal the start of a permanent low-inflation environment that is different from historical experience.

The extreme volatility in investment returns and the volatile nature of the investment environment highlighted in these examples point to the importance of applying informed judgements to changing investment environment circumstances when using ex post returns as a proxy for ex ante returns.

\subsection{Statistical analysis}

It is often argued that the use of realised equity premiums as a proxy for the expected equity premium implicitly assumes stationarity of $\varepsilon R P$, i.e. the true mean does not change with time.

On the other hand, non-stationary series often wander far from historical values, only returning to previous means in the long run and, in many cases, not at all. The implication is that a time series of ERP figures that contains a structural break cannot be used as proxy for expected returns.

There is limited empirical support for the stationarity of US ERP series. For example, Derrig and Orr (2003) examine the Ibbotson Associates 1926-2002 data series for stationarity, i.e. time invariance of the mean ERP, and found that stationarity cannot be rejected. However, no such empirical evidence exists for the SA ERP series. The aim of this section is to investigate the time- 
J de Beer

series properties of the historical share; bond and resulting equity return time-series.

\subsubsection{The data}

SA financial market data has only been systematically collected and published since 1960 . However, Firer and McLeod (1999) constructed the relevant indices and reported the history of SA cash, bond and equity markets from 1925 to 1998. This dataset was subsequently expanded and backdated to 1900 by Dimson, Marsh and Staunton and incorporated into the DMS global database, which contains annual returns on stocks, bonds, bills and inflation from 1900 for 17 countries, including South Africa. All index returns are computed as the arithmetic average of the individual security returns. DMS notes that their guiding principle was to avoid survivorship, success, look-ahead or any other form of ex post selection bias. The criterion was that each index should follow an investment policy that was specifiable in advance, so that an investor could have replicated the performance of the index, using information that would have been available at the time.

The data comes from the DMS global database (as described earlier in this section). This dataset is used to examine the historical equity returns, bond returns and resulting ERP data series for stationarity, i.e. time invariance of the mean $\varepsilon R P$, using the Augmented Dickey-Fuller test procedure. This may shed light on the question of the appropriateness of using the historical mean as an approximation of the expected $\varepsilon R P$.

\subsubsection{Empirical results}

TABLE 3: Descriptive statistics: real equity and bond returns, 1900-2005

\begin{tabular}{lcc}
\hline & Bonds & Equity \\
\hline Mean & 0.024490 & 0.089488 \\
Median & 0.020602 & 0.054189 \\
Maximum & 0.370686 & 1.028822 \\
Standard deviation & 0.105335 & 0.226482 \\
Kurtosis & 4.500989 & 5.539001
\end{tabular}

Source: Author's own calculations, using the DMS database

The empirical results show that the probability distribution of both equity and bond returns are non-normal: both exhibit positive skewness and are leptokurtic. This is in line with previous empirical studies for emerging market returns.

Visual inspection suggests that the real bond and equity returns, as well as the ERP series, are stationary. This is confirmed by econometric test results. Returns on equities, bonds and the resulting ERP re stationary: the null hypothesis of a unit root cannot be rejected at a $99 \%$ significance level. These results remain robust over different estimation periods. 
TABLE 4: Stationarity of bond, equity returns and ERP: results of augmented dickey-fuller tests

\begin{tabular}{cc}
\hline Critical values & Test statistics \\
\hline $1 \%$ level: -3.5 & Bonds: -9.295 \\
$5 \%$ level: -2.89 & Equity: -9.51 \\
$10 \%$ level: -2.58 & ERP: -9.35
\end{tabular}

Source: Author's own calculations, using the DMS database

\section{CONCLUSION}

The ERP research is not definitive. The long-term expected future equity risk premium is not directly observable, even in hindsight, and assessing a point estimate of this variable is not an easy task. A range of evidence has been presented in the literature, reflecting widely diverging estimates, mainly using US data. The consensus in the US has shifted over time from a strict reliance on the realised historical results to somewhat lower estimates using so-called supplyside models.

However, historically realised figures cannot be ignored in reaching an informed estimate. At the very least, they remain a useful framework for broad investment expectations. This is also the case in SA, as evident from the analysis in this paper. The analysis in this paper suggests that analysing past historical figures remains useful in the SA context. This is supported by the results of the econometric analysis, showing stationarity of the ERP time-series, meaning that the true mean does not change over time. This implies that the historical average mean may be used as a proxy for the long-run expected ERP. However, the well-documented problems relating to large standard errors (predictability problem) and relevance due to changing circumstances are also evident in the SA data. Thus, investors would be well advised to analyse the past and apply informed judgments as to future differences, if any, when attempting to arrive at fair forecasts. Macro-economic (domestic and global) factors, as well as factors such as market sentiment, should be considered when the relevance of historically realised investment returns for future expectations is evaluated.

\section{REFERENCES}

Arnott, D. \& Bernstein, P.L. (2002). What risk premium is normal? Financial Analyst Journal, 58 (2), pp. 64-86.

Arnott, D. \& Ryan, R. (2001). The death of the risk premium: consequences of the 1990s. Journal of Portfolio Management, 27(3), pp. 61-74.

Bradfield, D., Firer, C. \& Abrahams, Y. (2002). The attractiveness of the equity market as signalled by the market risk premium. Cadiz Quantitative Research publication.

Campbell, J.Y.; Diamond, P.A. \& Shoven, J.B. (2001). Estimating the real rate of return on stocks over the long term. Washington DC: Social Security Advisory Board. 
Campbell, J.Y. \& Shiller, R.J. (1998). Valuation ratios and the long-run stock market outlook. Journal of Portfolio Management, 28(2), pp. 11-26. (Updated in Cowles Foundations Discussion paper no 1295 , Yale University, March 2001).

Chan, L.K.C., Karceski, J. \& Lakonishok, J. (2001). The Level and Persistence of Growth Rates. (NBER Working paper no 8282).

Claus, J. \& Thomas, J. (2001). Equity premia as low as three percent? Evidence from analysts' earnings forecasts for domestic and international stock markets. Journal of Finance, 56(5), pp. 162916666.

Constantinides, G.M. (2002). Rational asset prices. Journal of Finance, 57(4), pp. 1567-1591.

Constantinides, G.M., Donaldson, J.B. \& Mehra, R. (2002). Junior can't borrow: a new perspective on the equity premium puzzle. Quarterly Journal of Economics, 117(1), pp. 269-296.

Derrig, R.A. \& Orr, E.D. (2004). Equity Risk Premium: Expectations Great and Small. North American Actuarial Journal, 8(1), pp. 45-69.

Diamond, P.A. (2000). What stock market returns to expect for the future? Social Security Bulletin, 63(2), pp. 38-52.

Digby, P., Firer, C. \& Gilbert, E. (2006). The South African equity risk premium. Journal of Studies in Economics and Econometrics, 30(3), pp. 1-17.

Dimson, E., Marsh, P. \& Staunton, M. (2006). The worldwide equity risk premium: a smaller puzzle. (Working paper). London: London Business School.

Dimson E., Marsh, P. \& Staunton M. (various issues). Global Investment Returns Yearbook. ABN Amro/London Business school.

Dimson, E., Marsh, P., \& Staunton M. (2003). Global Evidence on the Equity Risk Premium. Journal of plied Corporate Finance, 15(4), pp. 27-38.

Dimson, E., Marsh, P. \& Staunton, M. (2002). Triumph of the Optimists: 101 Years of Global Investment Returns. Princeton: Princeton University Press.

Elton, E.J. (1999). Expected Return, Realized Return, and Asset Pricing tests. The Journal of Finance, 104(4), pp. 1199-1220.

Fama, E.F. \& French, K.R. (2002). The Equity Premium. Journal of Finance, 57(2), pp. 637-659.

Firer, C. \& Staunton, M. (2002). 102 Years of South African Financial Market History. The Investment Analysts Journal, 57(5), pp. 57-65.

Glassman, J.K. \& Hasset, K.A. (2000). Dow 36000: The New Strategy for Profiting from the Coming Rise in the Stock Market. New York: Three Rivers Press.

Goyal, A. \& Welch, I. (2006). A Comprehensive Look at the Empirical Performance of Equity Premium Prediction, NBER Working Paper W10483. Massachusetts: National Bureau of $\varepsilon$ conomic Research.

Graham, J. \& Campbell, H. (2001). The Theory and Practice of Corporate Finance: Evidence from the Field. Journal of Financial Economics, 60(2), pp. 187-243.

Hunt, L.C. \& Hoisington, D.M. (2003). Estimating the Stock/Bond Risk Premium: an Alternative Approach. The Journal of Portfolio Management, 29(2), pp. 28-34.

Ibbotson, R.G. \& Chen, P. (2003). Long-run stock returns: participating in the real economy. Financial Analysts Journal, 59(1), pp. 88-98. 
Ibbotson, R.G. \& Sinquefield, R.A. (1976). Stocks, Bonds, Bills and Inflation: Year-By-Year Historical Returns (1926-1974). The Journal of Business, 49(1), pp. 11-47.

Illamen, A. (2003). Expected Returns on Bonds and Stocks. Journal of Portfolio Management, 29(2), pp. $7-27$

Jones, C.P. \& Wilson, J.W. (2005). The Equity Risk Premium Controversy. The Journal of Investing, 14(2), pp. 37-43

Jorion, P. \& Goetzmann, W.N. (1999). Global Stock Markets in the Twentieth Century. Journal of Finance, 54(3), pp. 953-980.

Jorion, P. \& Goetzmann, W.N. (1999). Re-Emerging Markets. (NBER Working paper no. 5906). Available from: http://ssrn.com/abstract=7704. (Accessed on 8 May 2007).

Kopcke, R.W. \& Rutledge, M.S. (2004). Stock Prices and the Equity Premium during the Recent Bull and Bear Markets. New England Annual Economic Review. Federal Reserve Bank of Boston, 10(1), pp. 63-84.

Lettau, M. \& Ludvigson, S. (2001). Consumption, Aggregate Wealth and Expected Stock Returns. Journal of Finance, 56(3), pp. 815-849.

Lettau, M., Ludvigson, S. \& Wachter, J.A. (2004). The Declining Equity Premium: What Role does Macro Economic Risk play?, NBER Working Paper No. 10270. Massachusetts: National Bureau of Economic Research.

Makina, D. \& Negash, M. (2005). Structural Changes and Dating of Stock Market Liberalisation: Evidence from the JSE. Journal of Studies in Economics and Econometrics, 29(2), pp. 61-76.

Mayfield, E.S. (2004). Estimating the Market Risk premium. Journal of Financial Economics, 73(3), pp. 465-496.

McCulloch, B. (2002). Estimating the Market Equity Risk Premium. (Working paper, New Zealand Treasury). Available at: http://www.treasury.govt.nz/workingpapers/2001/01-20.asp. (Accessed on 6 May 2007).

Mehra, R. (2003). The Equity Premium: Why is it a Puzzle? Financial Analysts Journal, 59(1), pp. 54-69.

Mehra, R. \& Prescott, દ. (2003). The Equity Premium in Retrospect in Constantinides, G.M, Harris, M. \& Stulz, R.M. (eds). Handbook of Economics and Finance. Amsterdam: Elsevier.

Mehra, R. \& Precott, E. (1985). The Equity Risk Premium: a Puzzle. Journal of Monetary Economics, 15(2), pp. 145-161.

Polk, C.K., Thompson, S.B. \& Vuolteenaho, T. (2004). New Forecasts of the Equity Risk Premium. AIA 2005 Philadelphia meetings. SSRN no 422901.

Ritter, J.R. \& Warr, R. (2002). The Decline of Inflation and the Bull Market of 1982-1999. Journal of Financial and Quantitative Analysis, 37(1), pp. 29-61.

Salomons, R. \& Grootveld, H. (2003). The Equity Risk Premium: Emerging versus Developed Markets. Emerging Markets Review, 4(2), pp. 121-144.

Shiller, R. (2000). Irrational Exhuberance. Princeton: Princeton University Press.

Siegel, J.J. (1999). The Shrinking Equity Premium: Historical Facts and Future Forecasts. Journal of Portfolio Management, 26(1), pp. $10-17$. 


\section{J de Beer}

Siegel, J. (2002). Stocks for the long run: the definitive guide to financial market returns and longterm investment strategies, 3rd edition. New York: McGraw-Hill.

Welch, I. (2000): Views of Financial Economists on the Equity Premium and Professional Controversies. Journal of Business, 73(4), pp. 501-537. 